\title{
The Use of Artificial Insemination (AI) Technology in Improving Milk, Beef and Reproductive Efficiency in Tropical Africa: A Review
}

\author{
Kubkomawa HI* \\ Department of Animal Production and Health, Federal Polytechnic, Nigeria
}

Submission: June 29, 2017; Published: March 23, 2018

*Corresponding author: Kubkomawa HI, Department of Animal Production and Health, Federal Polytechnic, Pmb 35, Mubi, Adamawa State, Nigeria, Tel: +2347066996221; Email: kubkomawa@yahoo.com

\begin{abstract}
The objectives of the study are to review AI practices as rapid means of improving milk, beef production and reproductive efficiency in tropical Africa. It is also to showcase the place of AI in livestock industry with the aim of encouraging farmers to adopt the technology for better livestock production and food sufficiency. AI is one of the assisted reproduction technologies (ARTs) used in many domestic species including bees and human beings. The use of AI is on the increase in horses, beef cattle, sheep, goats, deer, buffalo and dogs. AI has, also, been successful in conservation breeding of endangered species such as primates, elephants and wild felids. AI allows for widespread use of genetically superior sires that would normally not be available to breeders because they are too expensive to purchase. AI allows for faster and increased genetic improvement in cattle allowing for improved herd performance and productivity. It is the most commonly used assisted reproduction technologies (ART) in livestock, revolutionizing the animal breeding industry during the $20^{\text {th }}$ century. In contrast to medical use, where intrauterine insemination (IUI) is used only occasionally in human fertility treatment, $\mathrm{AI}$ is by far the most common method of breeding in intensively kept domestic livestock, such as dairy cattle (approximately 80\% in Europe and North America), pigs (more than $90 \%$ in Europe and North America) and turkeys (almost 100\% in intensive production). The other assisted reproduction technologies (ARTs) in animals are generally confined to specialist applications or for research purposes, since the cost would be prohibitive for normal livestock breeding. It is recommended that, Government and well to do stake-holders in the industry should encourage farmers by supplying semen, reliable methods of estrus detection and training AI personnel to achieve higher conception rates.
\end{abstract}

Keywords: Powerful tool; Milk; Beef production; Reproductive efficiency; Africa

Abbreviations: HF: Holstein Friesian; NAPRI: National Animal Production Research Institute; AI: Artificial insemination; ART: Assisted reproduction technologies; ET: Embryo transfer; IVF: In-vitro fertilization; ICSI: Intra-cytoplasmic sperm injection; GIFT: Gamete intra-fallopian transfer

\section{Introduction}

Reports have shown that, the rapid means of improving milk, beef production and reproductive efficiency is to combine the adaptability and hardiness of the Bos indicus with the genetically high reproductive and milk yield potentials of the Bos taurus through cross-breeding.To utilize the genetic advantage of the cross-breeding, many decades ago, Nigeria imported several Holstein Friesian (HF) sires for cross-breeding with the local breeds, especially Bunaji (White Fulani) cows. This effort resulted in a considerable improvement in milk production. The results of studies conducted at the National Animal Production Research Institute (NAPRI), Shika, Nigeria, on the performance of Friesian-Bunaji crossbreds indicated an improvement of about $60 \%$ in milk yield of the first cross, and further increase in the level of Friesian blood resulted in an additional gain in yield, but with decreasing magnitude and marked reduction in calving interval and age at first calving. Subsequently, livestock owners and breeders begin to show high interest in the use of exotic breeds or their frozen semen to upgrade the local indigenous dairy cows. The objectives of the study are to review AI practices as a rapid means of improving milk, beef production and reproductive efficiency in tropical Africa. It is also to showcase the place of $\mathrm{AI}$ in livestock industry with the aim of encouraging farmers to adopt the technology for better livestock production and food sufficiency.

\section{Artificial insemination (AI)}

According to DeForest [1] and Blacksburg [2] artificial insemination (AI) is the manual placement of semen in the reproductive tract of the female animal by a method other than natural mating. $\mathrm{AI}$ is one of the technologies usually referred to 
as assisted reproduction technologies (ART), in which, offspring are produced by enabling the meeting of gametes (spermatozoa and oocytes). Other techniques encompassed by ART include the following: in-vitro fertilization (IVF) where fertilization takes place outside the body; intra-cytoplasmic sperm injection (ICSI) which is a single spermatozoon caught and injected into an oocyte; embryo transfer (ET) where embryos that have been derived either in-vivo or in-vitro are transferred to a recipient female to establish a pregnancy; gamete intra-fallopian transfer (GIFT) where spermatozoa are injected into the oviduct to be close to the site of fertilization in-vivo; and cryo-preservation where spermatozoa or embryos, or occasionally oocytes are cryo-preserved in liquid nitrogen for use at a later stage.

\section{Semen collection}

According to Nafarnda [3] in most domestic animals, semen is collected by means of an artificial vagina, for example, from a bull, ram or stallion, after allowing the male to mount either an estrous female or a phantom. The artificial vagina comprises of a lubricated liner which is inserted into an outer jacket, between the two spaces filled with warm water. The pressure inside the artificial vagina is increased by addition of air. The ejaculate is collected and deposited into an insulated vessel attached to the end of the liner. But boar and dog semen are usually collected by manual stimulation. In some species such as dogs and marmoset monkeys that are adapted and can be easily handled, it is possible to collect semen by palpation or through vaginal washing after natural mating. However, in this situation, the spermatozoa have been exposed which may be dangerous to sperm survival. Human males can usually supply a sample by masturbation, except in the case of spinal injury when electro-ejaculation may be necessary. Some other primates can also be trained to supply semen samples on request in the same manner like human beings. In non-domestic species, electro-ejaculation is the only possible means of obtaining semen samples. The problem with electro-ejaculation is that, the secretions of the accessory glands may not be present in the usual proportions, which may have a detrimental effect on sperm survival.

\section{Semen constituents}

Semen consists of spermatozoa contained in a watery fluid known as seminal plasma that represents the combined secretions of the different accessory glands, such as the seminal vesicles, bulbourethral gland and prostate. The contributions of these different glands vary between species and environmental conditions. In some species, such as most primates, the semen coagulates immediately after ejaculation and then liquefies over a period of approximately 30 minutes. In most other species, the ejaculate remains liquid, the exception being in camels where the seminal plasma is highly viscous and does not liquefy readily in vitro. The addition of enzymes has been suggested as a means of liquefying primate or camel semen. However, all the enzymes tested thus far (collagenase, fibrinolysin, hyaluronidase and trypsin) have been seen to cause acrosomal damage in spermatozoa and are contraindicated if the spermatozoa are to be used for AI. Recent advances have shown that, camel semen extended 1:1 volume to volume, will liquefy in $60-90 \mathrm{~min}$ at 37 ${ }^{\circ} \mathrm{C}[4]$.

Seminal plasma contains an energy source (fructose), proteins and various ions such as calcium, magnesium, zinc and bicarbonate. Seminal plasma not only activates the spermatozoa, which have been maintained in a quiescent state in the epididymis, but also functions as a transport medium to convey the spermatozoa into the female reproductive tract and to stimulate her to allow spermatozoa to swim to the site of fertilization. It has been suggested that, seminal plasma, at least in horses, is also a modulator of sperm-induced inflammation, which is thought to play an important role in sperm elimination from the female reproductive tract [5]. Various types of protein in the seminal plasma, such as spermadhesins and the so-called CRISP (cysteine-rich secretory proteins) are thought to be associated with sperm viability. It may that, these protein types bind to spermatozoa immediately, setting in motion a series of intracellular events through a second-messenger pathway. In some species, small membrane-bound vesicles have, also, been identified in seminal plasma, seemingly beginning from distinct accessory glands in various species. These vesicles, variously named prostasomes, vesiculosomes, or epididysomes depending on their origin, fuse with the sperm outer membrane, increasing motility and possibly being involved in sperm capacitation and acquisition of fertilizing ability. However, their exact mechanism of action is yet to be elucidated.

Seminal factors promote sperm survival in the female reproductive tract, modulate the female immune response, tolerate the concept us, and to condition the uterine environment for embryo development and the endometrium for implantation [6]. The action in the endometrium is through the activation of macrophages and granulocytes, and also dendritic re-modelling that improves endometrial receptivity to the implanting embryo. The cytokine release has embryotrophic traits and may also influence tissues outside the reproductive tract. Contact to semen induces cytokine activation into the uterine luminal fluid and epithelial glycocalyx lining the luminal space. These cytokines act together with the developing embryo as it traverses the oviduct and uterus preceding implantation. Several cytokines are thought to be involved, for example, granulocytemacrophage colony stimulating factor (GM-CSF), a principle cytokine in the post-mating inflammatory response, which targets the pre-implantation embryo to promote blastocyst formation, thereby increasing the number of viable blastomeres by inhibiting apoptosis and facilitating glucose uptake [7]. According to Robertson, Mayerhofer, and Seamark [8]. Gutsche, Wolff, von Strowitzki, and Thaler [9] interleukin-6 (IL-6) and leukocyte inhibitory factor (LIF) are similarly induced after exposure to semen.

Clinical studies in humans showed acute and cumulative benefits of exposure to seminal fluid and, also, a partnerspecific route of action. According to studies by Bellinge et 
al. [10] and Tremellen et al. [11] live-birth rates in couples undergoing fertility treatments are improved if women engaged in intercourse close to embryo transfer. Research has also shown that, the use of seminal plasma pessaries by women suffering from recurrent spontaneous abortion is reported to improve pregnancy success. Partner-specificity of the response is suggested by increased rates of pre-eclampsia in pregnancies from donor oocytes or semen, when prior exposure to the donor sperm or concepts antigens has not occurred [12].

\section{Processing of semen}

Although seminal plasma plays an important role in the activation of spermatozoa and in the female reproductive tract, it is dangerous to long-term sperm survival outside the body. Under physiological conditions, sperm cells are activated by seminal plasma at ejaculation and then swim away from the site of semen deposition in the female reproductive tract. It is only during in-vitro storage that, sperm cells become in contact with seminal plasma long-term. Thus, it is customary to add a semen extender to the semen, to dilute toxic elements in seminal plasma, to provide nutrients for the spermatozoa during in-vitro storage and to buffer their metabolic by-products. The addition of extender, also, permits the semen to be divided into several semen doses, each containing a specific number of spermatozoa that has been determined to be optimal for good fertility in inseminated females [3].

\section{Preservation of semen}

Semen is used either immediately after collection (fresh) for example in turkeys, human beings; after storage at a reduced temperature (stored) for example in horses, pigs, dogs; or after freezing and thawing (cryo-preservation) for example in bulls [1-3].

Fresh semen: In contrast to animal species, human semen is not extended prior to processing and is not usually kept for more than a few hours before use. Poultry semen cannot be extended for too long as is done with other species since the sperm cells are adversely affected by increased dilution. Goat semen cannot be kept at $37^{\circ} \mathrm{C}$ because an enzymatic component of the bulbourethral gland secretion hydrolyses milk triglycerides into free fatty acids, which adversely affects the motility and membrane integrity of buck spermatozoa [13]. For liquid preservation, goat semen can be stored at the temperature of $4{ }^{\circ} \mathrm{C}$, although viability is retained for only $12-24$ hours. The extension rate used for stallion varies among countries as 1:2, 1:3 or even 1:4 (v/v) semen extenders. The normal practice in some countries is to have 500 million or one billion progressively motile spermatozoa for fresh or cooled semen doses respectively. Boar semen doses contain three billion progressively motile sperm cells.

Stored semen: Storing of extended semen at reduced temperature helps to extend sperm life by slowing their metabolism as well as by inhibiting bacterial growth. Bacteria grows by utilizing the nutrients in semen extenders, thus competing with spermatozoa for these limited resources, and release metabolic by-products, thus creating an environment that is not conducive to maintaining viable spermatozoa. Furthermore, as bacteria die, they may release endo-toxins that are toxic to sperm cells. Nevertheless, cooled stored semen is the common method used for breeding horses and pigs, enabling the semen dose to be transported to different locations for insemination. Stallion semen is normally stored at the temperature approximately $6{ }^{\circ} \mathrm{C}$ while boar semen is stored between 16 and $18^{\circ} \mathrm{C}$. Most boar semen doses are sold and served as cooled doses. In contrast, some stallions produce sperm cells that do not tolerate cooling, rapidly losing progressive motility. In such cases, the only option currently is to use fresh semen doses for AI immediately after semen collection, although a new method of processing, centrifugation through a single layer of colloid, has been shown to solve the problem discussed [3].

Cryo-preservation: Semen is most useful for AI if it can be cryo-preserved, since this method of preservation ideally enables the semen to be stored for an unlimited period without loss of quality until needed for AI. Since the frozen semen does not deteriorate in viability, it can be examined until the male has been shown to be free from disease at the time of semen collection. However, the sperm cells of various species differ in their ability to survive cryo-preservation. Ruminant sperm cells survive well, whereas poultry sperm cells do not, with less than $2 \%$ retaining their viability on thawing [14]. For farm animal breeding, the cost of cryo-preservation and the likelihood of a successful outcome following AI must be considered when deciding whether to use fresh, cooled or frozen sperm doses.

The spermatozoa are mixed with a protective solution containing lipoproteins, sugars and a cryo-protectant, such as glycerol. These constituents assist to preserve membrane reliability during the processes of cooling and re-warming. However, sperm motility must also be maintained, so that the thawed sperm cells can reach the oocytes after insemination and fertilize them. In most species, the seminal plasma is removed by centrifugation before mixing with the cryo-extender, for example, stallion, boar, goat and human semen. The extended semen is packed in straws before plunging into liquid nitrogen for longterm storage. There is still considerable variation in the success of sperm cryo-preservation between different species, despite intensive research into the constituents of cryo-extenders and the rates of cooling and re-warming. Human spermatozoa can be frozen relatively successfully using commercially available cryoextenders and programmable freezing machines. As previously mentioned, the ability of cryo-preserved spermatozoa to retain their fertilizing ability varies widely between species. New cryoextenders and new protocols are being developed constantly in an effort to address this issue. One recent advance has been the introduction of dimethylsulphoxide and the amides formamide and dimethylformamide as cryo-protectants, in place of glycerol. These molecules seem to function better than glycerol for some individuals whose sperm cells do not freeze well, for example, some stallions. The clarification with this observation is that, 
these molecules are smaller than glycerol and, therefore, may cause less damage when they penetrate the sperm membrane. However, no technique appears to be universally successful within one specie. As far as turkey spermatozoa are concerned, it seems that, the development of a successful freezing method will require more than new cryo-protectants and additives [15].

\section{Semen evaluation}

When choosing a male for breeding, especially for AI, it is imperative to assess its potential fertility by undertaking clinical and laboratory examinations. The in-vitro semen evaluation, complementary to the clinical examination, is of high diagnostic value for assessing testicular and epididymal function, and/or the genital tract of the male, allowing elimination of clear-cut cases of infertility or potential sub-fertility [16-18]. Likewise, the degree of normality of the semen before being processed for AI can be analyzed. The semen analysis routinely includes an immediate assessment of volume, appearance such as color, contamination, sperm concentration and motility, as well as later determination of sperm morphology and the presence of foreign cells. Once screened for normality, ejaculates preserved for AI are assessed for sperm concentration and sperm motility. These are the parameters most often used to determine sperm viability in post-thaw semen samples as well as to estimate breeding potential of a sire under field conditions $[16,17,19]$. Unfortunately, neither a simple semen analysis nor the routine evaluation postthaw enables the determination a priori of the potential fertility level that the analyzed semen will reach, particularly after AI. The usefulness of these parameters to measure fertility of a semen sample accurately is controversial [20] and correlations between sperm motility and fertility have revealed large ranges of variation [21-24]. Correlations between sperm morphology and fertility have, also, been found to vary widely, and have most often been statistically non-significant when the semen of AI quality grade has been assessed [17]. Researchers have, also, used additional laboratory assays to predict accurately the fertilizing potential of a semen sample. Individual laboratory assays, which evaluate a single parameter, are not effective predictors of fertility. However, a combination of several assays may provide a better prediction of fertility $[25,26]$. The testing of a large number of parameters should lead to a higher accuracy because fertilization is a multi-factorial process [27]. However, most of these analyses are expensive and time-consuming and cannot be applied under field and/or commercial conditions. Sperm analysis conducted under commercial conditions leads to the detection of ejaculates of very poor quality associated with poor fertility. However, the pre-selection of the samples, the high number of sperm per dose and the high quality of the semen used in the AI programs reduces the variability, giving a low probability of detecting fertility differences associated with seminal parameters [28].

\section{Sperm concentration}

Accurate and precise determination of sperm concentration in an ejaculate is important for AI programs in order to produce uniform insemination doses containing an adequate number of sperm. A certain safety margin is often used by AI stations to ensure that, all insemination doses contain a minimal number of sperm. This, also, implies that, some insemination doses contain an excessive number of sperm and that males of high genetic value are not used efficiently. This safety margin, also, affects the average revenue per ejaculate for the AI station. The concentration of sperm in a straw is dictated by factors that affect semen quality, which are usually based on how the semen survives the freezing and thawing process. Factors include breed of bull, bull to bull variation, and the time of the year the semen is collected. Dairy semen usually freezes better than bull's semen. The average number of sperm cells/straw is 20-40 million. Proportion of sperm that endure the thawing process is between 30 and $80 \%$, which is dependent on the factors listed above. The good AI sires will usually not release semen that has a post-thaw survival rate less than $30 \%$. Average number of live sperm cells/insemination dose is $5-10$ million. If the semen is gender selected, the straws will contain approximately 2 million sperm cells. Additionally, only $30 \%$ of the sperm survive the freezing and thawing process. Therefore, most companies that sell gender-selected sperm recommend that, it only be used on virgin estrous cycling yearling heifers [29-31].

The hemocytometer has often been referred to as the gold standard for assessing sperm numbers [29-31]. The equipment is slow, however, and multiple measurements of each sample are needed to obtain a precise result [31,32]. The use of a spectrophotometer is probably the most frequent method used by AI stations for assessment of sperm concentration [32,33]. For satisfactory results, periodic calibration of hemocytometers is necessary. The detection spectrum is inadequate for these instruments, and accurate quantification of sperm numbers in dilute or concentrated samples is challenging [29,34]. Spectrophotometers over-estimate sperm numbers in dilute semen samples and under-estimate sperm numbers in concentrated sperm samples. For individual raw ejaculates of boar semen, differences in the amount of gel particles or debris (cytoplasmic droplets, bacteria) can result in an inaccurate determination of the sperm concentration [33]. According to Evenson who reported that, electronic particle counters allow rapid determination of sperm concentration but tend to include any debris in the size range of sperm. Fluorometric measurements of the amount of DNA using DNA-specific fluorochromes have been studied by Fenton and Hansen [34,35] but this method requires stoichiometric staining of all DNA and minimal unspecific fluorescence from the extender.

\section{Sperm motility}

Most frequently, the semen quality of dairy bulls and boars in AI centers is evaluated using sperm concentration and motility in fresh and post-thaw semen for bulls. While studies by Correa et al. [23,36-38] have established a correlation between motility and field fertility, and others did not. Good progressive motility of spermatozoa is an indicator of both unimpaired metabolism 
and intactness of membranes [39]. Estimation of motility has fundamental importance in daily quality control of semen. The percentage of motile sperm cells is used to calculate the required degree of dilution and to estimate the number of intact sperm cells per insemination dose. Regular motility checks of boar semen after dilution and during the holding period furnish information on the capacity for preservation of the semen of each boar and its individual peculiarities. Motility is usually assessed visually via a light microscope. It is inexpensive and quick, but accuracy depends on the subjective estimation by individuals even though, surprisingly, consistent results can be obtained [33]. Objective Computer Assisted Sperm Analysis (CASA) systems have become commercially available, but these systems are not frequently used in commercial AI-centers because of the high investment costs [40]. Encouragingly, small sampling errors and high correlations with fertility have been reported [41] but the reported procedures have to be applied to an independent data set to test their repeatability. The main problem in CASA systems is related to the standardization and optimization of the equipment and procedures $[40,42]$. A simple visual estimation of sperm motility remains a useful tool for routine semen assessment for research purposes and in the AI industry.

As boar spermatozoa show a higher percentage of circular movement than those from other species, except stallions, it is recommended to estimate the different forms of motility, including proportions of progressive spermatozoa [39]. Estimates undertaken using phase contrast microscopy within 20-30 min of dilution cannot be integrated easily into the production processes. Stored semen should be examined regularly and motility values above $60 \%$ should be considered satisfactory [39].

\section{Sperm morphology}

Morphological abnormalities of sperm can have a detrimental impact upon fertilization and embryonic development $[18,43]$. Bulls and boars used for commercial AI are selected to a certain degree on the basis of a low incidence of morphologically abnormal spermatozoa, so that, statistical calculations concerning their correlation with fertility are not very informative [39,42], although some evidence for a relationship between sperm morphology and fertility in bulls has been presented $[44,45]$. A complete morphological examination is recommended when bulls and boars are introduced into the AI station and during subsequent regular routine examinations [39,45]. Principles for determining sample size for morphological assessment of spermatozoa were extensively discussed by Kuster, Singer and Althouse [46]. The percentage of cytoplasmic droplets in boar ejaculates used for AI should not exceed 15\%, especially when stored semen is used. In addition to the incidence of cytoplasmic droplets, the percentage of other morphological alterations should not exceed $20 \%$ [39].

A number of classification systems exist for morphological abnormalities of sperm, including primary and secondary defects, which classify sperm abnormalities on the basis of their presumptive origin [47] Major and minor defects-a revised system where sperm defects are classified in terms of their perceived adverse effects upon male fertility [48]; Compensable and uncompensable semen traits according to a theoretical increase in numbers of functionally competent sperm that will or will not solve the problem $[18,49,50]$. A compensable defect is one where the defective spermatozoa either do not reach the site of fertilization or fails to initiate the fertilization process. Defects that lead to failed fertilization or early pregnancy loss are termed uncompensable.

\section{The insemination dose}

The number of sperm in the insemination dose is an important factor affecting the probability that a female will become pregnant after AI, and in litter-bearing animals, also, the litter size [51]. To maximize pregnancy rate, the number of sperm in a dose is intentionally set high, but this management approach tends to obscure differences among males that might impact outcome of breeding when fewer sperm are used [33,5256]. Certain males achieve maximum fertility after AI with very few motile sperm (1 million for cattle), whereas for other males 20-30x more motile sperm are required to maximize fertility $[51,57,58]$. At high sperm numbers per AI dose, individual bulls differ in their maximal NR\%. That is unrelated to the rate at which they approach this maximum $[49,58]$. Vice versa, subfertile bulls could not be restored to normal fertility by increasing numbers of sperm per insemination. Data for cattle are most comprehensive, but it would be erroneous to assume that this principle, which results from so called "compensable defects" of sperm [50], is not operational in other species. Actually, it has been stated by several authors that, insemination trials with reduced sperm numbers are needed to reveal sub-fertile males and/or to detect differences between males $[33,33,52,56,59,60]$.

From the perspective of validating a diagnostic assay, the use of an excessive number of sperm when measuring fertility increases the probability that, the compensable defects in sperm will be masked $[33,54]$. A compensable defect is one in which low fertility can be overcome, at least in part, by increasing the number of sperm in the AI dose [12,58,50]. Low fertility caused by an uncompensable defect persists regardless of the number of sperm per insemination. Hence, with a compensable defect of sperm, the "problem" causing low fertility results from the failure of sperm characteristics being expressed before sperm enters the oocyte. An uncompensable defect involves an attribute (s) being expressed only after a spermatozoon enters an ovum [54]. When a spermatozoon with an uncompensable defect fertilizes an oocyte, it is unable to complete the fertilization process or sustain embryonal development, so pregnancy may not be detected.

There is an increasing interest among $\mathrm{AI} /$ breeding organizations to decrease the number of spermatozoa per straw to be used for AI, which may be related to economic revenues and the expected increased use of sex-sorted semen in bulls. It is generally accepted that, a total of $15 \times 106$ spermatozoa 
in a frozen $0.25 \mathrm{ml}$ straw is enough to achieve an acceptable fertilization rate in cattle provided that, post-thaw motility is equal to or above 50\% [61-63]. Extension of semen to low sperm numbers per AI-dose has been related to a decrease in bull sperm viability in-vitro with significant bull variation [63,64]. In AI of swine, several dose regimens are applied, ranging from $1.5 \times 109$ to $6.0 \times 109$ spermatozoa per intra-cervical insemination dose [16,65-67]. A lower sperm dose is more profitable for AI centers and makes more effective use of superior boars. However, when decreasing the insemination dose, the effect of semen quality becomes more important otherwise compensable morphological deficiencies can no longer be overcome [50,66-70]. This leads to decreased fertility rates and smaller litter sizes [66].

Cryo-preserved semen doses can be "quarantined" until the male is shown to have been free of disease at the time of semen collection. In contrast, the short shelf-life of fresh semen doses means that, they must be inseminated into the female before the disease-free status of the male has been established. Breeding males used for semen collection are tested routinely for the presence of antibodies in serum as being indicative of past infection, but some viruses, e.g. equine arteritis virus, may be shed in semen for several weeks before there is evidence of sero-conversion. In other cases, usually of congenital infection, individual animals may be permanent virus "shedders" without ever developing antibodies. Semen from these animals represents a source of pathogens for disease transmission to naive females.

Viral infections such as HIV and hepatitis can be removed from the semen of patients by a sequential method of sperm preparation, i.e. centrifugation on a density gradient followed by a "swim-up" [71,72]. Since sperm cells function as vectors for viruses, further work is required to investigate how closely different viral particles are associated with the sperm membrane with putative carry-over during processing. The double method of processing has, also, been successful in removing equine arteritis virus from an infected stallion ejaculate in a preliminary study [73]. Normally, in a healthy male, the ejaculate itself does not contain micro-organisms, but contamination occurs at semen collection from the prepuce and foreskin, the male's abdomen and the environment. Semen processing from animals usually takes place without access to a laminar airflow hood, resulting in potential contamination from the laboratory environment. Antibiotics are added to semen extenders to limit the growth of these contaminants and prevent disease in the inseminated females. Although the female reproductive tract has well-developed physiological mechanisms for dealing with contamination introduced during mating, these can be overwhelmed by bacteria multiplying in semen extenders or where semen is deposited in a non-physiological location.

The addition of antibiotics to semen extenders is controlled by government directives, both nationally and internationally, which state the types of antibiotic to be used and, also, their concentrations. In general, there is a tendency to use broad spectrum, highly potent antibiotics in various combinations to reduce sperm toxicity. However, these antibiotics may exacerbate the development of resistance, both for the people handling the semen extenders and in the environment during the disposal of unused extenders or semen doses. The scale of the problem becomes apparent if one considers that, approximately four million liters of boar semen extender containing antibiotics are used in Europe alone per year [3].

\section{Estrus detection}

Research has shown that, the most limiting factor in artificial insemination programs is the proper detection of cows or heifers in estrus. Estrus, or heat, is that period of time that occurs every 18-24 days in sexually mature, non-pregnant cows or heifers when they are receptive to mounting activity by bulls or other cows. In beef and dairy cattle operations where artificial insemination is the means of breeding the females, the herdsman must recognize and interpret a cow's heat signals. Proper timing of the artificial insemination is necessary to accomplish a high percentage of conception in the cows that are bred artificially. Considerable amounts of research have been conducted on the various factors contributing to the efficiency with which cows are detected in heat. When all is considered, one of the key factors is the skill of the human performing the heat detection. With an AI program, people assume the same responsibility as the bull for accurately detecting heat and the proper timing of insemination. Thus, the dilemma for the inseminator is determining which cows are in a "standing heat" and when that heat occurs. A cow is fertile only when an egg has been released (ovulated) from the ovary. This occurs about 10-14 hours after the period called "standing heat" ends. Because the sperm needs time in the cow's reproductive tract before they are capable of fertilizing the egg, insemination should be made several hours before ovulation. This means that, for the highest fertility, cows or heifers should be inseminated in the latter two-thirds of heat or within a few hours after having gone out of heat. This represents approximately 12-18 hours after the cow first comes in "standing heat $[74,75]$.

Heat detection efficiency (rate) is defined as the percentage of eligible cows that are actually seen or detected in heat. Several methods of calculating the efficiency with which heat is detected are available. A detection rate of 80-85 percent should be achievable. The detection rate can be measured by the 24 Day Heat Detection Rate Test, which is a test that the producer can implement to self-evaluate the heat detection efficiency (or inefficiency). In order for cows to be included in the test, they should be eligible to have heat cycles, at least 50 days postcalving for beef cows; be free of reproductive disorders such as cystic ovaries, pyometra, or other reproductive tract infections; and be non-pregnant. In addition, cows must have adequate body condition to expect most of them to be cycling. What producers are looking for is a group of cows that are most likely to display estrus in the next 24 days. Some of these cows will in fact be serviced during that interval, which will exclude them from the next 24-day list. At the end of the 24-day period, the number of cows detected in heat is divided by the total number of cows 
eligible to have estrous cycles. If the producer observes 50 cows but only 15 were detected in heat in 24 days, that gives a $30 \%$ detection rate-not too good. If the producer finds 40 or more cows in heat during the 24 -day test period for $80 \%$ or better detection rate, then a good AI program is possible. A second method of self-evaluation of heat detection can be performed by keeping an accurate record of heat dates. The average interval (in days) between detected heats is divided into the "expected" interval or 21 days. For example, if the average interval between detected heats for all eligible cows is 25 days, then the detection efficiency would be computed at $21 / 25$, or $84 \%[3,75]$.

\section{Signs of estrus}

According to some studies by Alm-Packalén [76]; Alphonsus et al. [74]; Mai et al. [75], the surest sign of estrus is that of a cow or heifer that permits other animals to mount her while she remains standing. This is the best sign of a cow's fertile period. Therefore, the most productive means of determining which cows are in "standing heat" is to observe the cattle carefully for about 30 minutes at least twice per day. More frequent observations may also be beneficial whenever it is practical. Estrous synchronization will aid in accurate heat detection and shorten the number of days that heat detection must be done. The best times of the day to observe cattle for heat detection are early in the morning and at the last daylight in the evening. However, heat detection while cattle are eating at feed-bunks or hayracks are difficult because hungry cattle are often more interested in the feed than in each other. Cornell University researchers describe the percentage of cows showing signs of heat at different times of the day. By far the largest percentage of cow's exhibit signs of estrus at the least convenient time of the day for accurate heat detection. This fact alone is considered a major cause of heat detection inefficiency. Many of the cows that do have a "standing heat" from midnight to 6 A.M. can be observed as having "secondary" signs of heat at the time of normal heat-detection on the previous evening. The secondary signs of heat include:

a. A willingness to mount other cows, even though neither cow may be willing to stand for the mount,

b. Roughened tail head or mud on the rump, which is evidence that other animals have tried to mount her,

c. Restlessness, which may be indicative of a cow about to exhibit heat (cows in pre-heat may bawl more than usual, head-butt, pace the fence, sniff or lick other cattle) and

d. Clear stringy mucus discharge which may be hanging from the vulva or smeared on the pin-bones or rump of a cow about to have estrus or one already in estrus. Bloody mucus often appears 2-3 days after estrus has occurred and should be recorded in order to closely watch for heat in 17-21 days.

Several aids to heat detection are available for producers with artificial insemination programs. These aids include chin-ball markers placed on androgenized cows or deviated "gomer" bulls.
This is a device similar to a ball-point pen that is strapped on the underneath side of the chin of an animal expected to mount cows or heifers in heat. The ink in the chin-ball marker leaves colorful streaks on the back or rump of a cow that has been mounted or was attempted to be mounted. Another commercially available aid to heat detection is the "Kamar heat-mount detector" (tradename). This device is glued to the rump (just forward of the tail head) of cows suspected to be in heat in the near future. Prolonged pressure (at least 3 seconds) from the brisket or chest of mounting animals will turn the originally white detector to red. Using the heat mount detector will be more effective in those pastures with little or no low-hanging tree limbs, brush, or back rubbing devices since false readings can occur. An economical heat detection aid is used at many U.S. dairies. This method is called "tail-chalking" and involves only the small expense of an oil-based "sale barn" paint stick. The paint stick is available at many farm and livestock supply stores and comes in a variety of colors. Orange is often the color of choice, especially with producers who are color-blind. The chalk (or livestock paint) is rubbed on the tail head of cows to be heat detected. The chalk should be placed from the imaginary line between the hook or hip bones back to and including the corner where the tail begins its vertical descent. Some producers choose to chalk in a narrow strip in summer months (after shedding has occurred) and wider bands on winter hair coats. Most tail-chalking veterans put the chalk in a strip two to three inches wide. The length is important because of the different contact points possible when the cow is mounted. In the spring, when cows are shedding, it is just about imperative that, the area be curry-combed so the applicator will deposit chalk instead of just rub off winter hair. Beef cattle producers can tail-chalk cows at about 50 days after calving, while the cows are crowded in a long walking chute or alley. Replacement beef heifers could be expected to have a high percentage of cycling animals when they are about 13-14 months of age and weigh approximately $65 \%$ of their expected mature body weight.

Reading the chalk strip is not hard but does require close observation and some practice. When a cow is just coming into heat and is being ridden but will not stand, the chalk will be slightly smeared. Also, it will often have some of the riding animal's hair in it and both the hair and chalk will be ruffled forward with a feathered appearance. When those conditions are spotted, write down the cow's number and watch her more closely. When she is in "standing heat" and is being ridden repeatedly, the chalk will be mostly rubbed off. This shows cow may have been in "standing heat" during the previous night. The cow should be watched to see if she does in fact allow other animals to mount her. If she does, then she is in "standing heat." If you do not observe the cow in "standing heat" but your barn records indicate that it is 18-24 days since she was last observed in heat or bred, then it is time for the cow to be bred. The rubbed off chalk indicates that, she has been in "standing heat" since you last observed her and still would be a good bet to inseminate. The oil-based chalk is relatively rain-resistant and unlikely to be 
rubbed off in brush. After seven to ten days, it will take on a flaky, crusted appearance as it dries. Some AI technicians choose to rechalk cows when the chalk becomes weathered and dried, but no signs of riding have been apparent. Occasionally, a cow will pick up the chalk. Usually, the obvious lick marks on the hair of the tail-head indicate that, she had not been ridden. Tail-chalking and other heat detection aids are tools to aid good heat detection. However, these "tools" should not be expected to replace the trusted method of spending a half-hour in the morning and a half-hour in the evening each day carefully observing the cattle.

\section{Induced ovulation}

When $\mathrm{AI}$ is performed in species that are normally induced ovulators, such as rabbits, cats and camels, it is necessary to stimulate ovulation. The easiest way to achieve this stimulation is to mate the female with a vasectomized male, but this practice is not desirable from the point of view of disease control and because it necessitates having vasectomized males available. The most acceptable alternative is to administer luteinising hormone, usually in the form of human chorionic gonadotrophin. However, the major disadvantage is that, repeated injections of this foreign protein may cause the female to develop antibodies, thus inactivating subsequent doses [3,74-76].

\section{Artificially induced ovulation}

Hormones may be administered to spontaneous ovulators to ensure that ovulation occurs at the correct time relative to AI. However, since 2006, the use of hormones in food-producing animals has been forbidden in the European Union, and local regulations may, also, apply in other parts of the world. Previously most dairy goats in France were inseminated out of the breeding season with deep frozen semen, after induction of estrus and ovulation by hormonal treatments. This protocol provided a kidding rate of approximately 65\% [77]. As an alternative to administering artificial hormones, out-of season breeding may be induced by altering the photoperiod or by introducing a buck to the herd. This practice is, also, widespread in intensive sheep flocks $[74,75]$.

\section{Time of artificial insemination}

Maximum fertility occurs when cows are bred near the end of "standing heat." Ovulation occurs about 12 hours after the end of standing heat. The 12-hour lead time allows the sperm cells to go through a process known as capacitation by the time the egg is released. Fertility decreases slightly when cows are bred a few hours on either side of this target, and decreased markedly when breeding occurs more than 12 hours away from the end of "standing heat." A guide that has proved to work well for timing $\mathrm{AI}$ is called the AM/PM rule. At the end of the morning heat detection period, animals detected the prior evening are bred; at the end of the evening heat detection period, those observed that morning are bred. In some situations, AI must be employed once-a-day wherein all animals detected in the prior 24 hours are bred. Some studies show little decrease in fertility when this approach is used [3].

\section{Semen handling}

Research has shown that, the information that identifies the semen is labeled 1AN001 while bull's breed (AN), AI center code (1), and bull's ID within AI center (100), Sire's name and registration number from his breed association. Collection date/ freeze code tells when the bull's semen was collected, processed, and frozen. Genders of sperm cells packaged are marked as either male or female. If the abbreviation CSS (Certified Semen Services) is on the straw, it means that, the semen was processed under the very strict health guidelines of CSS. Semen that is typically exported is processed according to CSS guidelines $[74,75]$.

The quality of frozen semen when it arrives at your farm or ranch is determined by the quality of the bull and organization that processed it. But once it arrives, it is up to you to take proper steps to ensure its viability. Frozen bull semen can be stored indefinitely, if it is maintained constantly at very low temperatures. The critical temperature is approximately -112 ${ }^{\circ} \mathrm{F}$. Semen which is exposed to temperatures warmer than -112 ${ }^{\circ} \mathrm{F}$ (even for a short time) and then returned to the storage tank may be damaged. The extent of damage depends upon how long the semen is exposed to the elevated temperatures. Although it is easy to maintain frozen semen at a safe temperature, it is also, easy to destroy it in a few moments of carelessness [3].

\section{Liquid nitrogen tank}

Studies have shown that, frozen semen is stored in liquid nitrogen at the temperature of $-196^{\circ} \mathrm{C}$ or in liquid nitrogen vapor $-180{ }^{\circ} \mathrm{C}$. Therefore, always proceed with caution when using liquid nitrogen. Store the tank in a dry, clean, well-ventilated area, off the floor and out of sunlight. For maintenance purposes, check the liquid nitrogen level frequently and make sure the tank is filled on a regular basis. Semen that has been thawed is no good. Frost or sweat on the tank is indicative of a tank that has developed a leak or has lost its vacuum. Extended and packaged semen can be stored indefinitely in liquid nitrogen [3,74-76].

The semen storage tank is a large vacuum-sealed metal bottle with an extremely efficient insulation system. Because of the vacuum bottle construction, the temperature can remain at $-320^{\circ} \mathrm{F}$ (liquid nitrogen temperature) as long as at least two inches of liquid nitrogen is present. Technical advances in design and construction have produced storage tanks with a liquid nitrogen holding time of six to nine months. Although semen storage tanks are well constructed, they still are susceptible to damage from mishandling. Avoid excessive movement of the tank. The inner chamber, which contains liquid nitrogen, is suspended from the outer shell by the neck tube. Any abnormal stress on the neck tube, caused by sudden jarring or an excessive swinging motion, can crack the tube. This results in vacuum loss from the outer chamber. To increase holding time, keep the tank in a cool location away from direct sunlight. Avoiding drafts from furnaces and outside air also helps prevent excessive nitrogen evaporation. However, make sure there is sufficient ventilation 
in the room to prevent possible suffocation which can be caused by excessive nitrogen gas in the air you breathe. Protect the tank from corrosion by keeping it elevated above concrete or wet floors. Use boards or pallets. Pick a location that is safe from children and vandals, but do not hide the tank; it must be placed where it can be seen daily and where it can be monitored routinely for nitrogen level. Finally, always be watchful for a lid that is left off and for frost or sweat on the tank. Give particular attention to the neck and vacuum fitting. Frost indicates that, the vacuum insulation has been lost, and liquid nitrogen has been or is evaporating rapidly. If you suspect this has happened, use a wooden yardstick to measure the amount of liquid in the tank. If the tank contains liquid nitrogen, the semen must be transferred to a good tank immediately. Should the tank be empty of liquid nitrogen it is doubtful that the semen is viable; it should be evaluated before it is used.

In the typical farm semen tank, dangerous temperatures exist in the upper half of the neck tube.

Exposure to these temperatures can occur when trying to locate a specific unit of semen or when transferring semen from tank to tank. Thermal injury to sperm is permanent and cannot be corrected by returning semen to liquid nitrogen. In order to minimize thermal damage: Identify which canister contains the desired semen. A semen inventory which keeps track of the location of each bull prevents unnecessary searching; Remove the canister from its storage position to the middle of the tank. Raise the canister just high enough in the neck region to grasp the desired cane of semen. Keep the canister tops no higher than the frost line, or keep the tops of the canes no higher than two to three inches from the tank's top; Grasp the desired cane, and immediately lower the canister to the tank floor. Keep the cane as low in the tank as possible while removing the unit of semen. Use tweezers to remove the straw. If the straw is located in the upper goblet, bend back the top tab of the cane to a 45 degree angle. This will keep the straw from bending or breaking. The straw should be removed within 10 seconds from the time the canister is raised into position; Immediately after the unit of semen is immersed in water, return the cane to the canister by raising the canister up over the cane. Return the canister to its storage position; any time it takes more than 8 to 10 seconds to locate a particular cane, the canister should be lowered back into the tank to cool completely. Never return a unit of semen to the tank once it has been removed from the cane [3].

\section{Thawing of semen and loading an AI gun}

Pre-warm AI gun and thaw bath at $95^{\circ} \mathrm{F}$. Check the breeding records to match the cow with semen she will be inseminated with. Move one straw of semen from the liquid nitrogen tank to the thaw bath as quickly as possible. $0.5 \mathrm{ml}$ or 0.25 French straws are thawed for $30-40$ seconds at $95^{\circ} \mathrm{F}\left(37^{\circ} \mathrm{C}\right)$. Minimize exposure of the straw to sunlight. Don't leave the semen in the water bath for an extended period of time of more than $15 \mathrm{~min}$ doesn't attempt to refreeze semen if not used. Throw it away!!
Note: The farther up the neck of the tank the semen is held, the greater the temperature and the increased risk of heat shock and the semen being damaged. Do not hold a canister or cane of semen above the neck of the AI tank any longer than 10 seconds. If you do, immerse the semen in the nitrogen for a short period of time. There is a frost line in the neck of the tank that indicates where a large temperature change occurs and you should try and keeps the semen below when removing straws from a cane. Wipe all water from the straw; check the bull's name on the straw. Is it correct? Clip the crimped end (opposite cotton plug) either with scissors or a cito-cutter. Place straw in a pre-warmed AI gun and place a sterile sheath over the gun and straw. Initiate the insemination process by rectally palpating the cervix through the rectum and prepare it to receive the insemination gun. Use a clean paper towel to wipe away any fecal material or mud from the external genitalia of the cow. Place the AI gun into the vagina at a slight angle with the tip of the AI gun pointing upward to avoid the opening of the urethra. Traverse the cervix with the AI gun and deposit the semen right at the tip of the cervical/uterine junction. Deposit the semen slowly (5 seconds) [3,74-76].

The correct thawing recommendation for semen in straws is not the same for all AI organizations. However, almost all organizations now recommend warm-water thawing of straws for 10 to 60 seconds. For optimum results, follow the specific recommendations of the semen processor. Breeders may use semen from various AI organizations, but practice only one thawing procedure. The National Association of Animal Breeders has recommended that, when in doubt, 90 to $95^{\circ} \mathrm{F}$ for a minimum of 40 seconds should be used as a universal thawing recommendation.

A major concern with warm-water thaw is the danger of cold shock when the straw is mishandled after thawing. Cold shock is the permanent injury to sperm caused by a sudden decrease in semen temperature after thawing. It occurs when the semen is thawed and then subjected to cold environmental temperatures before reaching the cow. The severity of damage depends on rate and span of temperature drop. If precautions are taken to prevent cold shock, the advantage of warm thaw will be realized. Here are some thawing tips: Always keep insemination equipment clean, dry and warm; Use a thermometer, do not guess at the temperature. Check the thermometer for accuracy at least every six months with a reference thermometer; Use an insulated water bath designed for thawing semen or a onepint wide-mouth thermos which is deep enough to immerse the entire straw. Recently, electronic thawing devices which maintain water temperature accurately between 95 and $98^{\circ} \mathrm{F}$ have been developed. These are convenient to use when breeding many cows at one time; never thaw more than one unit of semen at a time. As you breed your cows individually, so, you should also, thaw units of semen individually; Gently shake the straw as it is taken from the tank to remove any liquid nitrogen that may be retained in the cotton plug end of the straw. Time the thaw with a watch to avoid guessing. When possible or practical, use thawing 
recommendations of the AI organization from which the semen was processed.

\section{Handling of semen during insemination}

One of the most frequent chances for semen damage is during transport to the cow. After thawing, the semen temperature must be maintained as close to $95^{\circ} \mathrm{F}$ as possible. Handling thawed semen and preparing the insemination rod should be done in a sheltered, heated area. Proper steps for handling semen include: While the semen is thawing, warm the insemination rod by rubbing it briskly with a paper towel. In cold weather, place the warm rod within clothing so it will be close to the body and maintain warmth; After the semen is thawed for the required time, dry it thoroughly with a paper towel and protect it from rapid cooling; Adjust the air space in the straw to assure that, no semen is lost when the end of the straw is cut off. This can be done by slightly flicking the wrist while holding the straw at the crimp-sealed end; Transfer the straw to the rod and cut the tip of the crimp-sealed end of the straw squarely and through the air space. Only sharp scissors or a specially designed straw cutter should be used. Make sure to cut the straw "square" to achieve a good seal with the sheath; Wrap the assembled insemination rod in a clean, dry paper towel, and tuck it within your clothing for transportation to the cow. Do not place the rod in your mouth or carry it uncovered in your hand; Inseminate the cow within minutes after the semen has been thawed. The period of time between removing the semen from the tank and depositing the semen in the cow should not exceed 15 minutes.

When transferring semen between tanks, follow these tips: Have the tanks side by side and as close as possible. Fill the tanks with nitrogen before transfer, if possible; Have the appropriate canister in each semen tank in the center position; Transfer the canes quickly (within three to five seconds). Never touch the units of semen with bare fingers. It is essential that, frozen semen be handled and thawed carefully and properly in order to obtain optimum results. It is also, important to deal only with reputable, well-established AI organizations because their semen has been processed under standard, controlled conditions that are evaluated routinely.

\section{Insemination process}

Although, not part of the female genital tract, the rectum (terminal portion of the large intestine) is an important organ for you to become familiar with because your arm inside the cow will be working through this thin-walled tube. The rectum is 10 to 12 inches long and very stretchable. That is important because it is through the rectum that you will manipulate the cervix.

The anus serves as a valve between the rectum and the outside. It is made up of a circular (purse string) muscle located directly under the skin. It surrounds the very end of the rectum. Again, the anus is stretchable; hence, your hand and arm can easily slip into the rectum. Circular muscle contractions move along the rectal wall toward the outside. When strong, these contractions may block your hand from moving forward and make it difficult to manipulate the genital organs through the rectal wall.

The insemination process is quite straightforward. However, since relatively few sperm cells will be used, their placement is critical. The semen should be placed in the body of the uterus just in front of the cervix. You can recognize the proper site by the change in tissue consistency from firm and hard in the cervix to soft and spongy in the uterus. To achieve the highest possible fertility rate, semen should be deposited at the very front end of the cervix. The internal (or front) end of the cervix is often called the anterior cervical os. To deposit semen at this location requires the use of a special device called Cassou pipette or "AI gun." The recto-vaginal insemination process is used. The inseminator places his hand in the rectum and manipulates the reproductive tract so that, the gun passes through the vagina, then it is manipulated through the cervical rings, and then held at the internal opening of the cervix for semen deposition. In adequately restrained cattle this will take 30 seconds to 2 minutes. At first, however, passing an insemination syringe might not be easy because you might encounter natural obstructions on your way to the target. Beware of obstacles. The front end of the vagina forms a circular blind pouch where it joins the backward projecting cervix. This blind pouch is usually from 0.5 to 1 inch deep, surrounding the entire dome-shaped back end of the cervix. You'll meet other obstacles once you're inside the cervical canal. Firm, finger-like projections arranged in three to four circular rings extend into the canal. These cause the passageway to be crooked and contain blind pockets, or dead ends. The circular blind pouch of the vagina and the winding cervical canal with its dead ends are the two major stumbling blocks for anyone learning how to artificially inseminate. Next to estrus detection, semen placement error (by the technician) is most likely to affect fertility. Correct semen placement is very difficult to confirm in the field. It is impossible to check pipette placement. The pipette position changes too easily. Post-mortem tracts or examining culled cows inseminated with dye can be used to check semen placement after slaughter. Studies using dye deposition followed by slaughter have shown that, up to 70 percent of the cows are inseminated incorrectly. The dye was placed in the vagina, posterior cervix, uterine horn, or bladder. The target for semen deposition is the anterior cervix, a difficult site to find. Inexperienced inseminators often do not pass the pipette far enough, or they pass it too far into the uterine horns. Since the body of the uterus is only 0.5 to 0.75 inches in length, pipette passage of 1 inch into the uterus results in most of the semen entering only one horn, effectively reducing conception. Semen deposition is often made too rapidly, and semen takes the avenue of least resistance. If one horn is not as open as the other, it does not receive enough semen. Take your time while breeding a cow and depositing the semen. It only takes a few extra seconds to make sure semen is deposited correctly. The plunger should be depressed over a 5-second period, allowing the semen to flow slowly and evenly, divided between horns. In non-pregnant cows, walls of the uterus are soft and spongy. Inseminating syringes 
should never go beyond the front end of the cervix, because it is too easy to poke into or through the uterine wall. This could cause infection and perhaps even fatal peritonitis.

\section{Sanitary techniques during insemination}

During insemination, the inseminator is expected to wash his/her hands clean because inseminating cows is an invasion into the delicate uterine environment that is very conducive to bacteria growth. Bacteria on the inseminator's hands could be transferred to the inseminating gun during the loading procedure. If carried into the uterus during insemination, these organisms could thrive and grow rapidly resulting in metritis and infertility.

\section{Use of technicians/Inseminators}

Professional technicians are more successful at insemination than inexperienced owners or managers. Inseminators should periodically attend AI courses in order to improve or correct techniques. Selection of a qualified inseminator is an important element in the success of the artificial insemination program. While the insemination process is simple to understand, it does require considerable manipulative skill. Semen-selling companies conduct three or four day training programs, which will provide individuals with sufficient skill to begin inseminating. However, recently trained individuals generally experience lower conception rates until they have inseminated a number of animals. Regular practice at inseminating is required to maintain high conception rates. In many localities, AI studs have trained inseminators who provide insemination service for a reasonable fee. Cattle operations where artificial insemination is routinely used often have a well-trained individual who may be available as a technician. Before producers make a decision whether to hire a trained technician or to train a member of the farm team, they should weigh the considerable cost of a reduced conception rate during the learning process against the fees paid to a trained technician.

Successful AI, also, depends on depositing the semen in the female tract at around the time of ovulation. Like human beings, some domestic animals breed throughout the year, for example cattle and pigs, but others show a defined period of reproductive activity known as the breeding season, for example sheep and horses. The onset of the breeding season is controlled by photoperiod. Both of these patterns of reproductive behavior are characterized by waves of ovarian activity, culminating in ovulation. However, in some other species ovulation occurs in response to the stimulus of mating, for example, cats, rabbits and camels. In spontaneously ovulating species, ovulation occurs at some time during, or shortly after, estrus, which is the period of time when the female is receptive to the male. Since a successful outcome for AI depends on the deposition of spermatozoa at a suitable time relative to ovulation, estrus detection is crucial if the female is to be inseminated at the correct time. Males of the same species are, of course, very good at detecting estrus females, but since many livestock breeding units that practice AI do not have male animals in the vicinity, it is essential that husbandry personnel become good at recognizing estrous behaviour [7476].

Although some domestic animals may show well-developed estrous behavior, e.g. dairy cows, others may not. Behavioral signs of estrus in cows include restlessness or increased activity, vocalization, chin resting, swelling of the vulva, vaginal discharge and mounting other cows, although there are breed differences in the frequency and intensity of these signs. In sheep and goats, vulval swelling and vaginal discharge may be seen, and there is usually pronounced male-seeking behavior. When AI is to be used in sheep, it is usual to synchronize estrus with hormones: intravaginal sponges impregnated with progestagens are inserted to suppress the ewe's natural ovarian cycle for 12 days. On sponge removal, pregnant mare serum gonadotrophin is administered, with AI taking place at a set time thereafter. Alternatively, a vasectomised ram wearing a marker can be run with the females. When the females are in estrus, the vasectomised ram marks them as he mounts, thus enabling them to be identified for AI. Estrous sows and mares can be identified by the behavior exhibited towards teaser males.

There are differences between species in the site of semen deposition during natural mating. In ruminants and primates, semen is deposited in the vagina whereas in pigs, dogs, camels and horses, semen deposition is intra-uterine. In most species, it is possible to pass an insemination catheter through the cervix, thus enabling semen to be deposited in the uterus during AI. Exceptions are sheep and goats, where the tightly folded nature of the cervix does not permit easy passage of an insemination catheter. The advantages of depositing the semen in the uterus are that, the spermatozoa have less far to travel to reach the oviducts and fewer spermatozoa are lost through back-flow. A smaller volume of semen can be used per insemination dose than for intra-vaginal deposition, thus permitting an ejaculate to be divided into several AI doses, and the cervix, which can act as a barrier to the passage of spermatozoa, is bypassed. A disadvantage, particularly for human IUI is that, seminal plasma is also introduced into the uterus, unless specific steps are taken to separate the spermatozoa from seminal plasma before IUI.

\section{Specie differences in the use of AI}

Studies have shown that, despite the fact that, the basic principles of AI are the same in all species, there is wide variation in the uptake of this biotechnology in different species. In cattle, frozen semen doses are used most widely in Europe and North America, since there are well-established protocols for cryo-preserving bull semen. Semen doses typically contain approximately 15 million motile spermatozoa. In New Zealand, however, fresh semen doses are used instead, with AI occurring within $24 \mathrm{~h}$ of semen collection. The porcine AI industry uses liquid semen that has been stored for one to several days at 16-18 ${ }^{\circ} \mathrm{C}$. In contrast, AI with cryo-preserved boar spermatozoa results in lower far rowing rates and litter sizes than with cooled, stored 
spermatozoa, making the use of frozen-thawed sperm doses unattractive for commercial pig breeders. Exceptions to this rule are when semen is transported over long distances, which creates problems in temperature regulation and in instances where it is vital that the boars can be shown to be free of disease at the time of semen collection. The ability of boar spermatozoa to survive cool storage so well is attributed to low levels of reactive oxygen species (ROS) in semen or to the efficient scavenging of ROS by anti-oxidative components in seminal plasma.

AI has increased in horses in the last 25 years. Initially, fresh semen was used for AI shortly after semen collection, but nowadays the use of cooled semen has largely replaced fresh semen in Europe and North America. The extended semen is cooled to approximately $5{ }^{\circ} \mathrm{C}$, and transported in insulated containers, together with a cold pack. The fertility of the cooled semen is maintained for approximately $24 \mathrm{~h}$. Frozen semen doses are used infrequently, although this trend may change with the development of better freezing protocols. However, with the increased use of cooled semen, a concomitant decrease in foaling rate has been observed in several countries, such as Finland and Sweden, although the reason for this apparent decline in fertility is unknown. Unlike bulls and boars, which are selected for their semen quality as well as for their potential "genetic merit" in production characteristics (body composition, weight gain, milk production etc), the choice of stallions as breeding sires is based solely on their performance in competition. Thus, considerable variation in semen quality exists between stallions. This variation, coupled with increased use of a wider range of stallions, may be contributing to the observed decline in foaling rate. Other important considerations are the lack of established standard methods for cooling and freezing of stallion spermatozoa, for the sperm concentration in the insemination dose, or for quality control of raw or frozen/thawed spermatozoa.

Ram semen differs from stallion and boar semen in consisting of a small volume (a few $\mathrm{ml}$ ) of seminal plasma containing a very high concentration of spermatozoa. In Europe, reproductive research in livestock has tended to focus on cattle and pigs rather than on small ruminants, with the result that sperm handling and cryo-preservation for $\mathrm{AI}$ is less advanced in the latter species. In addition, the anatomy of the female reproductive tract in these species presents more of a barrier to successful insemination than in cattle, since the cervix is tightly folded, making insertion of the insemination catheter difficult. Productivity in sheep and goats could be increased, by improving the quality of the spermatozoa assigned for use in AI, and improving the AI techniques in these species. Recent innovations in sheep breeding include the development of a flexible catheter at the National Center for Genetic Resource Preservation, Fort Collins, Colorado, that can be inserted through the ovine cervix, thus overcoming the barrier to effective $\mathrm{AI}$ in this species.

$\mathrm{AI}$ in sheep and goats is traditionally performed with fresh or cooled spermatozoa, with acceptable fertility results. However, use of foreign breeds, genetic improvement and the use of "safe" semen from other countries requires the use of frozen semen, to enable analyses for contaminants or diseases in the "donor" male to be completed before the semen doses are used for AI. Although the post-thaw motility of frozen semen from goats and sheep is usually considered acceptable, low fertility has been associated with its use in AI, mainly owing to a shortened lifespan of the spermatozoa.

It is estimated that, $10-20 \%$ of couples wanting to conceive are unable to do so without some assistance. In $40 \%$ of cases, sub-fertility is due to female factors, with a further $40 \%$ being due to male factors. The remaining cases may be multi-factorial or idiopathic in origin. The use of IUI is generally contraindicated in male factor infertility, with IVF or ICSI being the treatments of choice. Since spermatozoa must be able to reach the site of fertilization and the products of conception must be able to reach the uterus for implantation, female factor infertility due to blockage of the oviducts is better treated by IVF or ICSI than by IUI. The patient's own semen or donor semen may be utilized for these fertility treatments.

AI can help to improve reproductive efficiency in animals for food production or sport. We are living in a world of scarce resources where there is constant competition for water, food, land and energy. Since protein of animal origin continues to be one of the most important forms of nourishment for human beings, animals are an essential part of the ecosystem and must be husbanded in a sustainable fashion. Animal production not only "competes" with human beings for the afore-mentioned resources, but also produces large amounts of effluent and gaseous emissions which can affect the environment. Therefore, it is vital for the survival of the planet that all aspects of animal production are justified and optimized. Through grazing or browsing and the recycling of nutrients, animals, also, contribute to maintaining the landscape in a productive state. The production of food of animal origin is based on breeding offspring to enter various husbandry systems. Therefore, one of the first points for optimization is in increasing reproductive efficiency, using a holistic approach. Females should be bred for the first time at an appropriate age to ensure the birth of healthy offspring and optimum lactation, without compromising the health of the female. Subsequent breeding attempts should, also, be timed appropriately to balance the metabolic requirements of lactation and early pregnancy. Females not conceiving or showing early embryonic loss should be identified at an early stage for re-breeding or culling. However, optimizing female reproduction demands a supply of spermatozoa. The spermatozoa must be readily available (i.e. can be stored), robust, and capable of fertilization, initiation of early embryonic development and regulation of placental formation, and there must be a means of delivery to an appropriate site in the female $[5,6,59]$.

AI in non-domestic species presents several new challenges compared with domestic species. In many cases little is known about the reproductive biology of the species in question, and handling the animals may cause them stress, with the attendant 
risk of injury. The animals must be managed correctly for the establishment and maintenance of pregnancy. There are reports of successful AI in deer, buffalo and camels [74-76].

\section{Reproductive performance in livestock following AI}

Reproductive ability is the primary source of all benefits derived from livestock, but earlier selective breeding has focused on increased animal production traits [54]. The most appropriate assessment of reproductive performance will vary depending on whether emphasis is placed on semen quality, differences among females or comparison of different AI strategies. In semen quality studies, reproductive success is often evaluated using the likelihood of conception after a particular AI [54]. Of the alternative outcomes after copulation or AI, non-pregnant or pregnant, pregnant is a better estimate of the normalcy of sperm function and non-pregnant of abnormal sperm function [54]. For the calving rate, there is a 9-month delay for data which is impractical for study purposes. For all types of assessments of reproductive performance, there are some potential systematic errors; including culling and selling of animals that one needs to be aware of when drawing conclusions. The many important aspects in determining differences in male fertility were critically reviewed by Amann \& Hammerstedt [14].

It is highly probable that, the use of AI in livestock will continue to increase. AI not only facilitates more effective and efficient livestock production, but can also be coupled to other developing biotechnologies, such as cryo-preservation, selection of robust spermatozoa by single layer centrifugation, and spermsex selection.

Apart from some specialist sheep or goat units focusing on milk production for cheese and intensive meat production, farming of these species tends to be confined to marginal land that is unsuitable for crop production or grazing for dairy cattle. There has been limited selection for production traits. However, there is a resurgence of interest in them now in developed countries because of growing awareness that, small ruminants could represent better utilization of scarce resources than larger ones, such as cattle, while producing less methane and effluent. In many developing countries, sheep and goats are better suited to the climate than cattle, and it is culturally acceptable to eat their meat and milk products. Thus, it is likely that, there will be an upsurge in the use of AI in sheep and goats in the future, with an emphasis on improving production traits by the introduction of superior genes. However, it is essential that, any AI scheme aimed at large scale improvement of the national herd must be supported by improved animal husbandry and animal health, otherwise the pregnancies resulting from AI will not go to term, and the offspring will either not survive or will fail to thrive. Many of the advanced ART are of little help in areas where basic husbandry skills are inadequate [74-76].

One potential disadvantage of $\mathrm{AI}$ is that, the natural selection mechanisms within the female reproductive tract to select the best spermatozoa for fertilization may be by-passed when AI is utilized. Biomimetics is the use of technologies and/or processes that mimic a naturally occurring event. Several in-vitro procedures have been suggested that could be used to mimic selection of good quality spermatozoa in the female reproductive tract and thus fit the definition of biomimetics in ART. These include sperm processing procedures such as swim-up, sperm migration, and filtration and colloid centrifugation [78]. Of these methods, the one that is most applicable to livestock and human spermatozoa is colloid centrifugation.

For many centuries, animal breeders and researchers have endeavored to control the sex of the offspring born, for various reasons. Initially male offspring were preferred for meat production, because of the better feed conversion efficiency and lean-to-fat ratio of males, whereas females were preferred for dairy purposes, except that some males of high genetic merit were still required as sires. Couples may want a child of a specific sex to avoid the expression of sex-linked disorders. Many methods have been proposed for separating X-and Y-chromosome bearing spermatozoa, based on physical properties, e.g. size of the sperm head, or functional properties e.g. swimming speed. However, the only method which has been shown to work reliably is that of selection and separation of spermatozoa whose DNA is stained with a bisbenzimidazole dye, H33342, using the sorting capacity of a flow cytometer $[79,80]$. This method functions because the $\mathrm{X}$-chromosome is larger than the $\mathrm{Y}$, therefore taking up more of the DNA-specific stain and showing a higher fluorescence when the spermatozoa are passed through a laser beam. In bulls, for example, the difference in DNA content between the X and Ychromosome is approximately $4.2 \%$. However, the process of sorting sufficient numbers for an insemination dose in the flow cytometer takes too long, since the stained spermatozoa must pass one at a time through a laser beam for detection of their DNA content. Moreover, the pregnancy rate after insemination of sexed bull spermatozoa is lower than with unsexed spermatozoa, making the procedure inefficient and expensive. Experience has shown that, the staining profiles are highly individual, with the result that, it is not possible to separate the X-and Y-chromosome bearing spermatozoa efficiently from all males.

Alternative methods of sex selection are, also, being investigated. Companies in Wales, Ovasort, have identified sexspecific proteins on the sperm surface and have raised antibodies to them. It is intended to use the antibodies to aggregate spermatozoa bearing a specific sex chromosome, thus enabling them to be removed from the general population. A combination of ARTs would, also, be relevant for sperm sexing. Thus, the speed of flow sorting can be increased by first removing the dead and dying spermatozoa from the population, for example by density gradient centrifugation or single layer centrifugation. Such a combination may increase the "sortability" of sperm samples. Sufficient sexed spermatozoa may be obtained from flow sorting for IVF, thus generating embryos or blastocysts for subsequent transfer. However, methods of speeding up the selection process are needed if flow cytometry is to become useful for species other than the bovine. 
It has been suggested that, AI and other forms of ART could be useful for genetic conservation and preservation of rare breeds. Many of these technologies have been successful to some degree in a research setting, but none have produced results sufficient to effect population-wide improvements in genetic management [81]. Cryo-preservation of semen has been the most widely applied ART in this respect, but much of the frozen semen in socalled gene banks has never been tested for fertility. A lack of suitable females or dearth of knowledge about the reproductive biology of the species involved may contribute to this deficit. However, long-term storage of frozen gametes of unknown fertility is not a sustainable policy for the conservation of rare breeds and endangered species. The development of in-vitro methods of testing sperm fertility would contribute considerably to conservation efforts. Since the semen quality in these animals may be poor [82], techniques such as SLC of samples prior to AI could be of considerable benefit in conservation breeding.

\section{Body condition score in breeding cattle}

Body condition scoring describes the systematic process of assessing the degree of fatness of an animal [83-85]. The score reflects the plane of nutrition on which an animal has been exposed over a reasonable length of time [86]. The loin, ribs, tail head, brisket, flank, vulva and/or rectum and udder are the important parts of the body used in determining the score. Physiologically, the proportion of protein and water of the animal's bodyweight decrease as it gains body condition [87].

Several authors have documented association between body condition scoring and fertility [88] and health [77]. The 6-point scale otherwise known as the Scottish or British system of scoring is, however, quite popularly used by dairy producers. The 9-point scale known as the American scoring system is recommended for tropical cattle, such as Bos indicus [89]. Body condition scoring is easy to apply and has been extensively used as a management tool largely in the dairy and beef sectors. It is, however, least reliable for calves and weaners, as they tend not to have heavy fat deposits.

Despite the reported repeatability estimates in experienced assessors, the general subjective nature of body condition scoring makes it difficult for inexperienced herd managers to correctly score the animals [90]. Unlike body weight measurements, the automation of body condition scoring have to date been unsuccessful [91]. There is a general consensus that, the genes that influence body condition scores and body weights are either closely linked or could have pleiotropic effects on each other. Berry et al. [92] observed a low correlation coefficient between body weight and condition scores. An objective indicator of nutritional status, which could be reliably and routinely used to aid management of cattle in rural areas, is to determine levels of nutritionally related blood metabolites $[93,94]$.

Earlier workers such as Lawman et al. [95] and Pullan [96] reported 6-point scale, with point 0 being animals that are severely emaciated and at the point of death, while point 1 has the animals that are emaciated and physically weak with all ribs and bone structure easily visible. Cattle in this score are extremely rare and are usually inflicted with a disease and/or parasitism [83-85]. In score 2, the cows appear emaciated, similar to BCS 1 , but not weakened. Muscle tissues seem severely depleted through the hindquarters and shoulders. Score 3 has animals that appear moderate to thin. The last two ribs could be seen and little evidence of fats is present in the briskets, over the ribs, or around the tail heads. The spine processes are smooth and not individually identifiable. Score 4 has animals appearing in very good flesh. The briskets are full, the tail heads show pockets of fats and the backs appear square due to fats. The ribs are very smooth and soft to handling due to fats cover. Score 5, cows are obese. Their necks are thick and short and their backs appear very square due to excessive fats. The briskets are distended and they have heavy fats pockets around the tail heads.

Body condition score (BCS) of beef cows at the time of calving has the greatest impact on subsequent re-breeding performance [97]. On the average, cows that calve in a BCS 3 or 4 have difficulty exhibiting their first heat by 80 days after calving. Whereas cows that calve in BCS 5 or 6 tend to exhibit heat by 55 days after calving and therefore, have a better opportunity to maintain a 365 day calving interval [97]. Although cows that calve in a BCS of 7 have a short postpartum interval, it is not economical to feed cows to a condition score of 7 .

Thin cows at calving (BCS 4 or thinner) produce less colostrum, give birth to less vigorous calves that are slower to stand and these calves have lower immunoglobulin levels, thus impairing their ability to overcome early calf-hood disease challenges. This illustrates the importance of targeting mature cows to calve in a BCS of at least 5 . Because 1st-calf-heifers have only reached about $85 \%$ of their mature weight after calving and require additional nutrients to support growth, they need to be fed so they have a BCS of 6 at calving.

Body condition scoring could be done using only visual indicators or a combination of visual and palpation of key bone structures for fat covers [97]. Palpation could be done during routine processing of cows through a chute. The key areas for evaluation are the backbone, ribs, hips, pin bones, tail head and brisket. Palpating cows for fatness along the backbone, ribs and tail head will help refine that skill of visual assessment of body condition. This is because using eyes to judge body condition can be difficult with cattle, like Highland or Galloway cattle, with the thick hair that hide a lot of what you can feel by touch. Other factors in addition to hair coat that can affect visual body condition scores are age of cow, rumen fill, and stage of pregnancy. Body condition scores should be recorded so that links to productivity and herd management can be examined. Several years of such information could reveal, for example, needed management changes. However, the greatest single factor influencing re-breeding performance of beef cows is body condition at calving, especially for spring-calving females. If producers wait until calving to manage body condition of their 
cows, they will find it very difficult and expensive to increase the body condition of a lactating cow.

Although evaluation of body condition could be looked at as an ongoing process, there are several key times when body condition scoring should be considered. These periods include late dry season in systems where females are managed almost entirely on vegetative or dormant grazed forage. For example, if cows are thin, early weaning should be considered. Nonlactating cows may pick-up condition by grazing forage alone or by feeding a small amount of supplement along with the grazed forage. Again, if young cows are thin and grass in the pasture is decreasing in nutrient quality, there is a need to strategically wean calves. Particular attention should be paid to young cows weaning their first calves, as they are most likely to be thin at this time. There may be need to consider early weaning of calves and giving cows access to higher quality forage.

For years, progressive cattle producers have recognized the important relationship between the physical appearance of their animals and reproductive performance outcomes. Body condition scores, also, allow producers to group cattle according to their nutritional requirements, thereby improving the efficiency of nutrition programs. Furthermore, body condition scores standardize the description of body condition in beef cows which greatly enhances communication among cattle producers, university educators, veterinarians and industry advisors Body condition scoring of cows allows for analysis of present management practices and application of research results and recommendations for individual cattle herds [98-100].

\section{Conclusion}

$\mathrm{AI}$ in animal production was originally developed to control the spread of disease, by avoiding the transport of live animals with potential pathogens to other animal units for mating and by avoiding physical contact between individuals. The use of semen extenders containing antibiotics also helped to prevent the transmission of bacterial diseases. The dairy industry's use of AI is a good example of how it can be used for herd improvement, i.e. milk production. AI allows for the practical use of genderselected semen, where high percentage of progeny ( $>90 \%)$ born are either male or female. AI allows for accelerated progeny testing of sires to determine their genetic potential. AI allows for the elimination of dangerous dairy bulls from the farm. It reduces number of bulls needed for natural service and allows the producer to use larger and heavier bulls on smaller animals without the danger of injury to the females. Progeny derived from the insemination process can be worth more money and allows for introduction of new genetic material via importation of semen from outside the country. No expensive handling, quarantine, and shipping costs of live animals. Frozen semen can be stored and used long after the donor or sire is dead. It enables breeding between animals in different geographic locations, or at different times (even after the male's death). It, also, allows for the use of semen from an injured sire that is unable to breed naturally.
AI allows for more efficient use of estrous synchronization, the process of breeding cows over a 3 to 7 day period compared to 21 days in unsynchronized animals. Breeding can occur in the event of physical, physiological or behavioral abnormalities. AI is a powerful tool when linked to other reproductive biotechnologies such as sperm cryo-preservation and sperm sexing and can be used in conservation of rare breeds or endangered species.

\section{Recommendations}

Despite the economic gains of AI, most semen is inexpensive, additional costs associated with $\mathrm{AI}$ such as the labor required for estrus detection, the need for an experienced AI technician, and drug cost of estrus synchronization are also capital intensive. Facilities that allow proper restraint of cattle are required so that cattle can be inseminated. Adequate physical facilities and nutritional resources are, also, required to handle a large number of cattle during the time period when cattle are being inseminated. Government and all stake-holders should work hand-in-hand to make AI less expensive and accessible to all farmers. This will also encourage the wide adoption of the technology in Nigeria and the tropical Africa at large for better production of animal products and ensure food security.

\section{References}

1. DeForest WI (1988) Estrous synchronization and artificial insemination in beef herds. A.I. Management Manual ( $2^{\text {nd }}$ edn) American Breeders Service, Virginia Cooperative Extension Service, pp. 400-434.

2. Blacksburg VA (1988) Recommended minimum standards for artificial insemination training. National Association of Animal Breeders. Columbia, MO Semen-handle with care. (1987) Virginia Polytechnic Institute, Blacksburg VA.

3. Nafarnda WD, Kubkomawa IH, Mshellia A, Nesati YI (2005) Evaluation of Fertility Rate in Friesian and White Fulani (Bunaji) Breeds of Cattle Following Artificial Insemination. Global Journal of Agricultural Science 14(2): 155-157.

4. Wani NA, Billah M, Skidmore JA (2007) Studies on liquefaction and storage of ejaculated dromedary camel (Camelus dromedarius) semen. Anim Reprod Sci 109: 309-318.

5. Troedsson MH, Loset K, Alghamdi AM, Dahms B, Crabo BG (2001) Interaction between equine semen and the endometrium: the inflammatory response to semen. Anim Reprod Sci 68: 273-278.

6. Robertson SA (2005) Seminal plasma and male factor signaling in the female reproductive tract. Cell Tissue Res 322: 43-52.

7. Robertson SA, Sjoblom C, Jasper MJ, Norman RJ, Seamark RF (2001) Granulocytemacrophage colony-stimulating factor promotes glucose transport and blastomere viability in murine preimplantation embryos. Biol Reprod 64: 1206-1215.

8. Robertson SA, Mayerhofer G, Seamark RF (1992) Uterine epithelial cells synthesize granulocyte-macrophage colony-stimulating factor and interleukin-6 in pregnant and non pregnant mice. Biol Reprod 46: 1069-1079.

9. Gutsche S, Wolff M, von Strowitzki T, Thaler CJ (2003) Seminal plasma induces mRNA expression of IL-1 $\beta$, IL- 6 and LIF in endometrial epithelial cells in vitro. Mol Hum Reprod 9: 785-791.

10. Bellinge BS, Copeland CM, Thomas TD, Mazzucchelli RE, O Neil G et al. (1986) The influence of patient insemination on the implantation rate in an in vitro fertilization and embryo transfer program. Fertil Steril 46: 2523-2526. 
11. Tremellen KP, Valbuena D, Landera SJ, Ballesteros A, Martinez J et al (2000) The effect of intercourse on pregnancy rates during assisted human reproduction. Hum Reprod 15: 2653-2658.

12. Salha O, Sharma V, Dada T, Nugent D, Rutherford AJ et al. (1999) The influence of donated gametes on the incidence of hypertensive disorders of pregnancy. Hum Reprod 14: 2268-2273.

13. Pellicer Rubio M, Combarnous Y (1998) Deterioration of goat spermatozoa in skimmed milk-based extenders as a result of oleic acid released by the bulbourethral lipase BUSgp60. Journal Reprod Fertil 112: $95-105$.

14. Wishart GJ (1985) Quantitation of the fertilising ability of fresh compared with frozen and thawed fowl spermatozoa. British Poultry Science 26: 375-380.

15. Holt WV (2000) Basic aspects of frozen storage of semen. Anim Reprod Sci 62: 3-22.

16. Martin Rillo S, Martinez E, Garcia-Artiga C, De Alba C (1996) Boar semen evaluation in practice. Reprod Dom Anim 31: 519-526.

17. Rodriguez Martinez H (2003) Laboratory semen assessment and prediction of fertility: still utopia? Reprod Domest Anim 38: 312-318.

18. Saacke RG (2008) Sperm morphology: Its relevance to compensable and uncompensable traits in semen. Theriogenology 70: 473-478.

19. Correa JR, Pace MM, Zavos PM (1997) Relationships among frozenthawed sperm charasteristics assessed via the routine semen analysis, sperm functional tests and fertility of bulls in an artificial insemination program. Theriogenology 48: 721-731.

20. Januskauskas A, Söderquist L, Håård MG, Håård MC, Lundeheim N, et al. (1996) Influence of sperm number per straw on the post-thaw sperm viability and fertility of Swedish red and white A.I. bulls. Acta Vet Scand 37: 461-470.

21. Kjaestad H, Ropstad E, Berg KA (1993) Evaluation of spermatological parameters used to predict the fertility of frozen bull semen. Acta Vet Scand 34: 299-303.

22. Stalhammar, EM, Janson L, Philipsson J (1994b) The impact of sperm motility on non-return rate in preselected dairy bulls. Reprod Nutr Dev $34: 37-45$

23. Tardif S, Laforest JP, Cormier N, Bailey JL (1999) The importance of porcine sperm parameters on fertility in vivo. Theriogenology 52: 447 459.

24. Januskauskas A, Johannisson A, Rodriguez-Martinez H (2003) Subtle membrane changes in cryopreserved bull semen in relation with sperm viability, chromatin structure, and field fertility. Theriogenology 60: 743-758.

25. Ericsson SA, Garner DL, Thomas CA, et al. (1993) Interrelationships among fluorometric analyses of spermatozoal function, classical semen quality parameters and the fertility of frozen-thawed bovine spermatozoa. Theriogenology 39: 1009-1024.

26. Gil MA, Roca J, Cremades T, Hernandez M, Vazquez, et al. (2005) Does multivariate analysis of post-thaw sperm characteristics accurately estimate in vitro fertility of boar individual ejaculates? Theriogenology 64: 305-316.

27. Amann RP (1989) Can the fertility potential of a seminal sample be predicted accurately? Journal of Androl 10: 89-98.

28. Gadea J, Selles E, Marco MA (2004) The predictive value of porcine seminal parameters on fertility outcome under commercial conditions. Reprod Domest Anim 39: 303-308.

29. Christensen P, Stryhn H, Hansen C (2005) Discrepancies in the determination of sperm concentration using Burker-Turk, Thoma and Makler counting chambers. Theriogenology 63: 992-1003.
30. Kuster C (2005) Sperm concentration determination between hemacytometric and CASA systems: why they can be different. Theriogenology 64: 614-617.

31. Prathalingam NS, Holt WW, Revell SG, Jones S, Watson PF (2006) The precision and accuracy of six different methods to determine sperm concentration. Journal of Androl 27: 257-262.

32. Evenson DP, Parks JE, Kaproth MT, Jost LK (1993) Rapid determination of sperm cell concentration in bovine semen by flow cytometry. Journal of Dairy Sci 76: 86-94.

33. Woelders H (1991) Overview of in vitro methods for evaluation of semen quality. Reprod Dom Anim Suppl 1: 145-164.

34. Fenton SE, Ax RL, Cowan CM, Coyle T (1990) Validation and application of an assay for deoxyribonucleic acid to estimate concentrations of bull sperm. Journal of Dairy Sci 73: 3118-3125.

35. Hansen C, Christensen P, Stryhn H, Hedeboe (2002) Validation of the FACSCount AF system for determination of sperm concentration in boar semen. Reprod Domest Anim 37: 330-334.

36. Correa JR, Pace MM, Zavos PM (1997) Relationships among frozenthawed sperm charasteristics assessed via the routine semen analysis, sperm functional tests and fertility of bulls in an artificial insemination program. Theriogenology 48: 721-731.

37. Holt C, Holt WV, Moore HD, Reed HC, Curnock RM (1997) Objectively measured boar sperm motility parameters correlate with the outcomes of on-farm inseminations: results of two fertility trials. J Androl 18: 312-323.

38. Christensen P, Brockhoff PB, Lehn-Jensen H (1999) The relationship between semen quality and the non-return rate of bulls. Reprod Dom Anim 34: 503-507.

39. Johnson LA, Weitze KF, Fiser P, Maxwell WM (2000) Storage of boar semen. Anim Reprod Sci 62: 143-172.

40. Verstegen J, Iguer-Ouada M, Onclin K (2002) Computer assisted semen analyzers in andrology research and veterinary practice. Theriogenology 57: 149-179.

41. Farrell PB, Presicce GA, Brockett CC, Foote RH (1998) Quantification of bull sperm characteristics measured by computer- assisted sperm analysis (CASA) and the relationship to fertility. Theriogenology 49: 871-879.

42. Rodriguez-Martinez H, Larsson B, Pertoft H (1997) Evaluation of sperm damage and techniques for sperm clean-up. Reprod. Fertil Dev 9: 297-308.

43. Walters AH, Eyestone WE, Saacke RG, Pearson RE, Gwazdauskas FC (2005a) Bovine embryo development after IVF with spermatozoa having abnormal morphology. Theriogenology 63: 1925-1937.

44. Söderquist L, Janson L, Larsson K, Einarsson, S (1991) Sperm morphology and fertility in A.I. bulls. Zentralbl. Veterinarmed A 38: 534-543.

45. Al Makhzoomi A, Lundeheim N, Haard M, Rodriguez-Martinez H(2008) Sperm morphology and fertility of progeny-tested AI dairy bulls in Sweden. Theriogenology 70: 682-691.

46. Kuster CE, Singer RS, Althouse GC (2004) Determining sample size for the morphological assessment of sperm. Theriogenology 61: 691-703.

47. Barth AD, Oko RJ (1989) Abnormal morphology of bovine spermatozoa. Ames, IA: Iowa State University Press.

48. Blom E (1983) Sygelige tilstande i konsorganer og sperma som kassationsårsag ved import og eksport af avlstyre til og fra Danmark. Pathological conditions in the genital organs and in the semen as ground for rejection of breeding bulls for import or export to and from Denmark. Nord Vet 35: 105-130. 
49. Saacke RG, Nadir S, Nebel RL (1994) Relationship of semen quality to sperm transport, fertilization, and embryo quality in ruminants. Theriogenology 41: 45-50.

50. Saacke RG, Dalton JC, Nadir S, Nebel RL, Nebel RL, Bame JH (2000) Relationship of seminal traits and insemination time to fertilization rate and embryo quality. Anim Reprod Sci 60(61): 663-677.

51. Flowers WL (2002) Increasing fertilization rate of boars: Influence of number and quality of spermatozoa inseminated. Journal of Anim Sci 80: E47-53.

52. Colenbrander B, Kemp B (1990) Factors influencing semen quality in pigs. Journal of Reprod Fertil Suppl, 40: 105-115.

53. Amann RP, Ha merstedt RH(1993) In vitro evaluation of sperm quality: an opinion J Androl 14: 397-406.

54. Amann RP, Hammerstedt RH (2002) Detection of differences in fertility. Journal of Androl 23: 317-325.

55. Amann RP (2005) Weaknesses in reports of fertility for horses and other species. Theriogenology 63: 698-715.

56. Ruiz-Sanchez AL, Odonoghue R, Novak S, Dyck MK (2006) The predictive value of routine semen evaluation and IVF technology for determining relative boar fertility. Theriogenology 66: 736-748.

57. den Daas N (1992) Laboratory assessment of semen charasteristics. Anim Reprod Sci 28: 87-94.

58. den Daas JH, De Jong G, Lansbergen LM, Van Wagtendonk-De Leeuw AM (1998) The relationship between the number of spermatozoa inseminated and the reproductive efficiency of individual dairy bulls Journal of Dairy Sci 81: 1714-1723.

59. Watson PF, Behan JR (2002) Intrauterine insemination of sows with reduced sperm numbers: results of a commercially based field trial. Theriogenology 57: 1683-1693.

60. Ardon F, Dohring A, Le Thi X, Weitze KF, Waberski D (2003) Assessing in vivo fertilizing capacity of liquid-preserved boar semen according to the Hanover gilt model. Reprod Dom Anim 38: 161-165.

61. Shannon P, Vishwanath R (1995) The effect of optimal and suboptimal concentrations of sperm on the fertility of fresh and frozen bovine semen and a theoretical model to explain the fertility differences. Anim Reprod Sci 39: 1-10.

62. Vishwanath R, Shannon P (2000) Storage of bovine semen in liquid and frozen state. Anim Reprod Sci 62: 23-53

63. Ballester J, Johannisson A, Saravia F, Haard M, Gustafsson H, Bajramovic D (2007) Post-thaw viability of bull AI-doses with low-sperm numbers. Theriogenology 68: 934-943.

64. Garner DL, Thomas CA, Allen CH (1997a) Effect of semen dilution on bovine sperm viability as determined by dual-DNA staining and flow cytometry. Journal of Androl 18: 324-331.

65. Colenbrander B, Feitsma H, Grooten HJ (1993) Optimizing semen production for artificial insemination in swine. Journal of Reprod. Fertil Suppl 48: 207-215.

66. Althouse GC (1997) Evaluating porcine semen for artificial insemination. Part I. Standard tests. Comp. Cont. Ed. Pract. Vet, 19:S30-S35

67. Althouse GC (1997) Evaluating porcine semen for artificial insemination. Part II. Assessment of cell membranes and viability. Comp. Cont. Ed. Pract. Vet, 19:400-404.

68. Althouse GC (1997) Comparison of currently used semen extenders in the swine industry. Comp Cont Ed Pract Vet 19: 777-782.

69. Johnson WH (1997) The significance to bull fertility of morphologically abnormal sperm. Vet Clin North Am Food Anim Pract 13: 255-270.
70. Althouse GC, Wilson ME, Kuster C, Parsley M (1998) Characterization of lower temperature storage limitations of fresh- extended porcine semen. Theriogenology 50: 535-543.

71. Englert Y, Lesage B, van Vooren JP, Liesnard C, Place I, et al. (2004) Medically assisted reproduction in the presence of chronic viral disease. Hum Reprod Update 10: 149-162.

72. Politch JA, Xu C, Tucker L, Anderson DJ (2004) Separation of human immunodeficiency virus type 1 from motile sperm by the double tube gradeint method versus other methods. Fertil Steril 81: 440-447.

73. Morrell JM, Geraghty RJ (2006) Effective removal of equine arteritis virus from stallion semen. Equine Veterinary Journal 38: 224-229.

74. Alphonsus C, Akpa GN, Barje PP, Nwagu BI, Orunmuyi M (2014) Evaluation of Fertility Traits Of Friesian X Bunaji Dairy Cows. Animal Research International 11(1): 1851 - 1862.

75. Mai HM, Voh Jr, AA, Deshi PS (1014) Some Fertility Indices in an Artificially Inseminated Bunaji and Bokoloji Herds in Kaduna State. Nigeria, Global Veterinaria 12(2): 171-175.

76. Alm-Packalen K (2009) Semen quality and fertility after artificial insemination in dairy cattle and pigs. Academic Dissertation presented, at the Faculty of Veterinary Medicine, University of Helsinki, for public criticism in the Walter Auditorium, Agnes Sjoberginkatu 2, Helsinki, on $5^{\text {th }}$ June, 2009

77. Leboeuf B, Delgadillo JA, Manfredi E, Piacere A, Clément V et al. (2008) Management of Goat Reproduction and Insemination for Genetic Improvement in France. Reprod Dom Anim 43(2): 379-385.

78. Morrell JM, Rodriguez Martinez H (2009) Biomimetic techniques for improving sperm quality in animal breeding: a review. The Open Andrology Journal 1: 1-9.

79. Morrell JM, Keeler KD, Noakes DE, MacKenzie NM (1988) Sexing of sperm by flow cytometry. Veterinary Record 122: 322-324.

80. Johnson LA, Flook JP, Hawk HW (1989) Sex preselection in rabbits: live births from $\mathrm{X}$ and $\mathrm{Y}$ sperm separated by DNA and cell sorting. Biol Reprod 41: 199-203.

81. Morrow CJ, Penfold LM, Wolfe BA (2009) Artificial insemination in deer and nondomestic bovids. Theriogenology 71: 149-165.

82. Gamboa S, Machado Faria M, Ramalho-Santos J (2009) Seminal traits, suitability for semen preservation and fertility in the native Portuguese horse breeds Puro Sangue Lusitano and Sorraia: Implications for stallion classification and assisted reproduction. Anim Reprod Sci 113: 102-113.

83. Gatenby RM (2002) Sheep. The tropical agricultulist ( $2^{\text {nd }}$ edn), MacMillan Publishers CTA. Wageningen AJ, Netherlands, Europe.

84. Todd RB (2008) Getting those repeat breeders bred. Western dairy news, Agrilife Extention and Research, University of Texas, USA.

85. Addass PA (2011) Effect of age and body condition score on sperm production potential among some indigenous bull cattle in Mubi Adamawa state, Nigeria. Agricultural and Biological Journal of North America 2(2): 203-206.

86. Stuth W, Dyke P, Jama A, Corbett J (1998) The use of NIR/NUBTAL, PHYGROW, and APEX in a meta-modelling environment for an early warning system to monitor livestock nutrition and health. National Workshop on Early Warning System for Monitoring Livestock Nutrition and Health. Addis Ababa, Ethiopia, pp. 59 -107.

87. NRC (1996) Nutrient requirements of beef cattle, ( $7^{\text {th }}$ revised edn), National Research Council Update 2000. National Academic, Press, Washington DC, USA.

88. Buckley F, OSullivan K, Mee JF, Evans RD, Dillon P (2003) Relationships among milk yield, body condition, cow weight, and reproduction in spring-calving Holstein-Fresians. Journal of Dairy Sci 86: 2308-2319. 
89. Nicholson MJ, Butterworth MH (1986) A guide to condition scoring of zebu cattle. International Livestock Centre for Africa, Addis Ababa .

90. Ferguson JD, Galligan DT, Thompson N (1994) Principal predictors of body condition scores in Holstein cows. Journal of Dairy Sci 77: 26952703.

91. Berry DP, Obrien B, OCallaghan EJ, Osullivan K, Meaney WJ (2006) Temporal trends in bulk tank somatic cell count and total bacterial count in Irish dairy herds during the past decade. Journal of Dairy Science 89: 4083-4093.

92. Roche JR, Berry DP (2006) Peripaturient climatic, animal and management factors influencing the incidence of milk fever in grazing systems. Journal of Dairy Sci 89: 2775-2783.

93. Oulun Y (2005) Variation in the blood chemical constituents of reindeer, significance of season, nutrition and other extrinsic and intrinsic factors. Dissertation presented to the faculty of science, university of Oulun, Finland.

94. Agenas S, Heath MF, Nixon RM, Wilkinson JM, Phillips CJC (2006) Indicators of under-nutrition in cattle. Animal and Wild Life Journa 15(2): 149-160.
95. Lawman BG, Scott NH, Somerville SH (1976) Condition scoring of cattle. The East of Scotland College of Agriculture Bulletin 6: 59-75.

96.Pullan NB (1978) Condition scoring of White Fulani cattle. Tropical Animal Health and Production 10: 118-120.

97. Ndlovu T, Chimonyo M, Okoh AI, Muchenje V (2007) Assessing the nutritional status of beef cattle: Current practices and future prospects. African Journal of Biotechnology 6(24): 2727-2734.

98. Akpa GN, Alphonsus C, Abdulkareem A (2012) Evaluation of herd structure of white Fulani cattle holdings in Zaria, Nigeria. Scientific Research and Essays 7(42): 3605-3608.

99. FAO (1996) World development report paper no. 2. Food and Agricultural Organization. Rome, Italy.

100. INEC (1996) Political and administrative demarcation of Adamawa State. Independent National Electoral Commission, Lagos, Nigeria.

\section{Your next submission with Juniper Publishers will reach you the below assets}

- Quality Editorial service

- Swift Peer Review

- Reprints availability

- E-prints Service

- Manuscript Podcast for convenient understanding

- Global attainment for your research

- Manuscript accessibility in different formats

( Pdf, E-pub, Full Text, Audio)

- Unceasing customer service

Track the below URL for one-step submission https://juniperpublishers.com/online-submission.php 